\title{
HIV Evolution: A Quantification of the Effects Due to Age and to Medical Progress
}

\author{
Guglielmo D’AMICO ${ }^{1}$, Giuseppe DI BIASE ${ }^{1}$, Jacques JANSSEN ${ }^{2}$, \\ Raimondo MANCA ${ }^{3}$ \\ ${ }^{1}$ Department of Drug Sciences \\ via dei Vestini, 31, 66013 Chieti, Italy \\ ${ }^{2}$ Cesiaf, Euria, Univ. de Bretagne Occ. \\ 6 av. L. Gorgeu, 29238 Brest, France \\ ${ }^{3}$ Department of Mathematics for the Economics, Financial and Insurance Decisions \\ via del Castro Laurenziano 9, 00161 Rome, Italy \\ e-mail:dibiase@unich.it
}

Received: October 2009; accepted: October 2010

\begin{abstract}
This paper offers an analysis of HIV/AIDS dynamics, defined by CD4 levels and Viral load, carried out from a macroscopic point of view by means of a general stochastic model. The model focuses on the patient's age as a relevant factor to forecast the transitions among the different levels of seriousness of the disease and simultaneously on the chronological time. The third model considers the two previous features simultaneously. In this way it is possible to quantify the medical scientific progresses due to the advances in the treatment of the HIV. The analyses have been performed through non-homogeneous semi-Markov processes. These models have been implemented by using real data provided by ISS (Istituto Superiore di Sanità, Rome, Italy). They refer to 2159 subjects enrolled in Italian public structures from September 1983 to January 2006. The relevant results include also the survival analysis of the infected patients. The computed conditional probabilities show the different responses of the subjects depending on their ages and the elapsing of time.
\end{abstract}

Keywords: non-homogeneous semi-Markov processes, survival analysis, age dependent model, chronological time dependent model, HIV/AIDS.

\section{Introduction}

In this paper three non homogeneous semi-Markov (NHSM) models are proposed as a useful tool for predicting, from a macroscopic point of view, the evolution of the Human Immunodeficiency Virus (HIV) infection.

CD4+ and viremia characterize simultaneously the states of the model. In fact the marker of HIV infection is the progressive depletion of a class of lymphocytes named $\mathrm{CD} 4+$ whose decline leads to opportunistic infections and unusual tumours. Moreover the presence of plasma viremia is strictly correlated with the possibility to the worsening of the disease.

The NHSM models with respect to standard epidemiologic data analyses, have huge advantages. They include: (a) the randomness both in the different states of the infection 
and in the time spent in each state; (b) the evolution of the infection taking into account also the different ages of the patients; (c) the improvements of disease through interrelated states; (d) few and weak hypotheses; (e) the conclusions are based on a list of all computed probabilities descending directly from observed data through nonparametric models.

Among recent papers using semi-Markov models in biomedicine see Davidov and Zelen (2000); Foucher et al. (2005); Mathieu et al. (2007). Apart from Foucher et al. (2005) and Mathieu et al. (2007), in all the papers quoted the model solvability is connected to the possibility that a patient might move through the states following the same direction. Interestingly, our data set shows that there are no negligible probabilities of recovering from the disease, and so the uni-directionality hypothesis for the state transitions has been removed, as in Di Biase et al. (2007). In the quoted article, the dynamic evolution of the infection has been analysed in a homogeneous framework using only immunological markers. Among the fundamental statistical references see Andersen et al. (1993); Gill (1980); Ouhbi and Limnios (1999); Limnios and Ouhbi (2005) and Dabrowska and Ho (2006).

In the opinion of doctors, HIV fully satisfies the few, weak working hypotheses needed.

\section{HIV Evolution Scheme}

Follow-up took 23 years. The retrospective study concerned a cohort of $K=2159$ HIVpositive enrolled in the Italian public structures from September 1983 to January 2006. The database has been provided by ISS (Istituto Superiore di Sanità). The study has been made by means of 37041 checkups.

In order to predict the HIV evolution, we took the following immunological states related to CD4+ counts and to viral load, as in Foucher et al. (2005) and Mathieu et al. (2007), plus an absorbing state (the death of the patient):

$$
\begin{aligned}
& \text { state I }\left(\mathrm{VL} \leqslant 400 \mathrm{cp} / \mathrm{ml} \text { AND CD4 }>200 \times 10^{6}\right. \text { cells/L); } \\
& \text { state II }\left(\mathrm{VL} \leqslant 400 \mathrm{cp} / \mathrm{ml} \text { AND CD } \leqslant 200 \times 10^{6}\right. \text { cells/L); } \\
& \text { state III }\left(\mathrm{VL}>400 \mathrm{cp} / \mathrm{ml} \text { AND CD } 4>200 \times 10^{6}\right. \text { cells/L); } \\
& \text { state IV }\left(\mathrm{VL}>400 \mathrm{cp} / \mathrm{ml} \text { AND CD4 } \leqslant 200 \times 10^{6}\right. \text { cells/L); } \\
& \text { state D (absorbing state: death of the patient). }
\end{aligned}
$$

Notice that state I represents the best state for a HIV-positive patient whereas state IV is the worst. No exact order relation between states II and III is established by Centre Disease Control guidelines.

We make the assumption, therefore, that the HIV/AIDS infection moves between five different grades of seriousness. All that led to the following set of states:

$$
E=\{\mathrm{I}, \mathrm{II}, \mathrm{III}, \mathrm{IV}, \mathrm{D}\}
$$

In Fig. 1 the graph model is pictured. It shows all the immunological states a HIV infected patient can go into. All the states apart from than D are inter-related, and also 


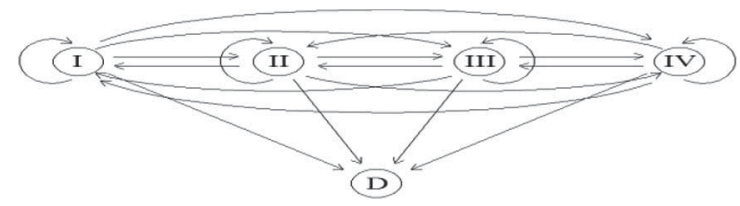

Fig. 1. Immunological/viral model stages an infected patient can go into.

improvements are considered. It is also possible that an examination will show that the patient's state has not changed.

\section{Age-Time Dependence Stochastic Model}

This model uses three sequences of random variables, see Janssen and Manca (1997) and, more recently, D’Amico et al. (2010):

$$
J_{n}: \Omega \rightarrow E, \quad T_{n}: \Omega \rightarrow \mathrm{N}, \quad A_{n}: \Omega \rightarrow \mathrm{N} ; \quad n \in \mathrm{N}
$$

The meaning of the variables is the following:

$J_{n}$ represents the state at the $n$th transition and expresses the possible stages in which the infection may show its level of seriousness;

$T_{n}$ represents the chronological time in which the $n$th transition occurred;

$A_{n}$ represents the age of the patient when she/he had the $n$th transition.

The process $\left(J_{n}, T_{n}\right)$ is assumed to be a discrete time non-homogeneous Markov Renewal Process. The age process $A_{n}$ is defined by the following relation:

$$
A_{n+1}=A_{n}+T_{n+1}-T_{n}
$$

where $A_{0}$ is known.

The main assumption is to consider the triple $\left(J_{n}, T_{n}, A_{n}\right)$ as a multidimensional non-homogeneous Markov Renewal Process with kernel

$$
Q_{i j}^{a}(s, t)=P\left[J_{n+1}=j, T_{n+1} \leqslant t \mid J_{n}=i, T_{n}=s, A_{n}=a+s\right],
$$

representing the probability that a patient is in state $j$ of the disease at the $(n+1)$ th transition within chronological time $t$, given that at the $n$th transition she/he entered state $i$ at time $s$ being aged $a+s$. In such a way the model is able to consider transition probabilities taking into account both the patient's age and the medical scientific progress due to the chronological time effect. The medical scientific progress are due to the creation of diagnostic medicine systems, see for example Maciulis et al. (2009).

The dependence of the transition rates on the age of the patient is considered using a semi-Markov model with age index.

The following extensions are straightforward:

$$
{ }^{a} p_{i j}(s)=\lim _{t \rightarrow \infty}{ }^{a} Q_{i j}(s, t) ; \quad i, j \in E, s, t \in \mathbb{N}, s \leqslant t, a \in \mathbb{N} .
$$


The matrix ${ }^{a} \mathbf{P}(s)=\left[{ }^{a} p_{i j}(s)\right]$ is the transition matrix of the embedded nonhomogeneous Markov chain for all starting age $a$.

The probability of making next transition before time $t$ being in state $i$ at time $s$ with age $a+s$ is given by:

$$
{ }^{a} H_{i}(s, t)=\mathrm{P}\left[T_{n+1} \leqslant t \mid J_{n}=i, T_{n}=s, A_{n}=a+s\right]=\sum_{j \in E}{ }^{a} Q_{i j}(s, t) .
$$

The conditional waiting time distribution in state $i$ given next state will be $j$ is

$$
\begin{aligned}
{ }^{a} G_{i j}(s, t) & =\mathrm{P}\left[T_{n+1} \leqslant t \mid J_{n}=i, J_{n+1}=j, T_{n}=s, A_{n}=a+s\right] \\
& = \begin{cases}{ }^{a} Q_{i j}(s, t) /{ }^{a} p_{i j}(s), & \text { if }{ }^{a} p_{i j}(s) \neq 0, \\
1, & \text { if }{ }^{a} p_{i j}(s)=0 .\end{cases}
\end{aligned}
$$

Now let ${ }^{a} N(t)=\sup \left\{n \in \mathbb{N}: T_{n} \leqslant t \mid T_{0}=0, A_{0}=a\right\}$ be the number of transition up to time $t$, then the NHSMP ${ }^{a} Z(t)=J_{a_{N}(t)}, t \in \mathbb{N}$ can be defined. Its transition probabilities are defined in the following way:

$$
{ }^{a} \phi_{i j}(s, t)=\mathrm{P}\left[{ }^{a} Z(t)=\left.j\right|^{a} Z(s)=i, T_{N(s)}=s, A_{N(s)}=a+s\right] .
$$

They are obtained by solving the following evolution equations:

$$
{ }^{a} \phi_{i j}(s, t)=\delta_{i j}\left(1-{ }^{a} H_{i}(s, t)\right)+\sum_{\beta=1}^{m} \sum_{\vartheta=s+1}^{t}{ }^{a} b_{i \beta}(s, \vartheta) \cdot{ }^{a+\vartheta-s} \phi_{\beta j}(\vartheta, t),
$$

where

$$
\begin{aligned}
{ }^{a} b_{i j}(s, t) & =P\left[J_{n+1}=j, T_{n+1}=t \mid J_{n}=i, T_{n}=s, A_{n}=a+s\right] \\
& = \begin{cases}{ }^{a} Q_{i j}(s, t)-{ }^{a} Q_{i j}(s, t-1), & \text { if } t>s, \\
0, & \text { if } t=s .\end{cases}
\end{aligned}
$$

The first term $\delta_{i j}\left(1-{ }^{a} H_{i}(s, t)\right)$ represents the probability of staying in state $i$ from time $s$ up to time $t$ given the entrance in state $i$ at time $s$ with age $a+s$. This probability contributes to ${ }^{a} \phi_{i j}(s, t)$ only if $i=j$.

The second term $\sum_{\beta=1}^{m} \sum_{\vartheta=s+1}^{t}{ }^{a} b_{i \beta}(s, \vartheta) \cdot{ }^{a+\vartheta-s} \phi_{\beta j}(\vartheta, t)$ represents the probability of entering in any state $\beta$ at any time $\vartheta$ with next transition given the entrance with last transition in state $i$ at time $s$ with age $a+s$. Then all possible trajectories bringing from state $\beta$ at time $\vartheta$ with age $a+\vartheta-s$ to state $j$ at time $t$ are considered by ${ }^{a+\vartheta-s} \phi_{\beta j}(\vartheta, t)$.

Algorithms to solve equation (7) are described in Janssen and Manca (1998). 
The effects of non-homogeneity and that of the patient age can be translated to the survival function and related metrics. Barbu et al. (2004) presented a homogeneous discrete time semi-Markov model for reliability and survival analysis. Blasi et al. (2004) studied the non-homogeneous case.

Here, we define reliability indicators with age dependence in the non-homogeneous case.

Let us consider the hitting time of state D given the entrance in state $i$ at time $s$ with age $a+s$ :

$$
{ }^{a} T_{i, D}(s)=\inf \{t \in \mathbb{N}, t>s: Z(t)=\mathrm{D}\}
$$

Then, the non-homogeneous reliability (or survival) function with age can be defined as follows:

$$
\begin{aligned}
{ }^{a} S_{i}(s, t) & =P\left({ }^{a} T_{i, \mathrm{D}}(s)>t\right) \\
& =P\left[{ }^{a} Z(u) \in U:\left.\forall u \in(s, t] \cap \mathbb{N}\right|^{a} Z(s)=i, T_{N(s)}=s, A_{N(s)}=s+a\right] .
\end{aligned}
$$

It represents the probability that the patient will survive up to time $t$ given the entrance into degree of illness $i$ at time $s$ with an age of $a+s$.

This probability is given by

$$
{ }^{a} S_{i}(s, t)=\sum_{j \in U}{ }^{a} \phi_{i j}(s, t)
$$

It should be noted that some common indicators in reliability theory such as the availability and maintainability are useless in our model. In fact, since the only bad state is an absorbing one (dead of the patient), this implies that the availability and the reliability functions correspond. Moreover, the maintainability function doesn't make sense.

We can define the non-homogeneous age indexed failure rate:

$$
{ }^{a} \lambda_{i}(s, t)=P\left({ }^{a} T_{i, \mathrm{D}}(s)=\left.t\right|^{a} T_{i, \mathrm{D}}(s) \geqslant t\right),
$$

and, adapting the analysis of Barbu et al. (2004) at our general framework, it is possible to prove that

$$
{ }^{a} \lambda_{i}(s, t)= \begin{cases}1-\frac{{ }^{a} S_{i}(s, t)}{{ }^{a} S_{i}(s, t-1)}, & \text { if }{ }^{a} S_{i}(s, t-1) \neq 0 \\ 0, & \text { otherwise. }\end{cases}
$$


The knowledge of the reliability function gives us also the possibility to compute the conditional expected time of death:

$$
\begin{aligned}
{ }^{a} E D_{i}(s) & =E\left[{ }^{a} T_{i, \mathrm{D}}(s)\right]=\sum_{n \geqslant s} n \cdot P\left({ }^{a} T_{i, \mathrm{D}}(s)=n\right) \\
& =\sum_{n \geqslant s} P\left({ }^{a} T_{i, \mathrm{D}}(s)>n\right)=\sum_{n \geqslant s}{ }^{a} S_{i}(s, n)=\sum_{n \geqslant s} \sum_{j \in E}{ }^{a} \phi_{i j}(s, n) .
\end{aligned}
$$

\section{The Model Implementation}

The proposed model is very general and provides diversified and abounding information. To get these advantages it is necessary to pay for them and the money is the availability of an huge database (for example from sub-Saharan Africa, Asia-Pacific region or European database). Unfortunately our database is national. For this reason, in order to achieve statistical significance of the results, we considered the two fundamental aspects of the age and medical scientific progresses separately. To this end two particular cases of the general model are implemented.

In order to consider the effects due to patient's age we consider only two sequences of random variables:

$$
J_{n}: \Omega \rightarrow E, \quad A_{n}: \Omega \rightarrow \mathrm{N} ; \quad n \in \mathrm{N} .
$$

As in the general model, $J_{n}$ represents the state at the $n$th transition, that is the possible stage in which the infection may show its level of seriousness and $A_{n}$ represents the age of the patient when she/he had the $n$th transition. It is supposed that the process $\left(J_{n}, A_{n}\right)$ is a non homogeneous Markovian renewal process with kernel $\mathbf{Q}=\left[Q_{i j}(s, t)\right]$ defined in the following way:

$$
Q_{i j}(s, t)=P\left[J_{n+1}=j, A_{n+1} \leqslant t \mid J_{n}=i, A_{n}=s\right]
$$

It represents the probability that a patient is in state $j$ at the $(n+1)$ th transition within the $t$ th year of its life, given that she/he entered state $i$ of the disease at age $s$ at the $n$th transition.

In order to consider the effects due to medical scientific progress we consider the following sequences of random variables:

$$
J_{n}: \Omega \rightarrow E, \quad T_{n}: \Omega \rightarrow \mathrm{N} ; \quad n \in \mathrm{N} .
$$

$J_{n}$ has the same meaning as before and $T_{n}$ represents the chronological time in which the $n$th transition occurred. It is supposed that the process $\left(J_{n}, T_{n}\right)$ is a non homogeneous Markovian renewal process with kernel $\mathbf{Q}=\left[Q_{i j}(s, t)\right]$ defined as follows:

$$
Q_{i j}(s, t)=P\left[J_{n+1}=j, T_{n+1} \leqslant t \mid J_{n}=i, T_{n}=s\right]
$$


It represents the probability that a patient is in state $j$ of the disease at the $(n+1)$ th transition within the chronological time $t$, given that she/he entered state $i$ at time $s$ with the $n$th transition.

In order to get the claimed results, we need to estimate the semi-Markov kernel $\mathbf{Q}=\left[Q_{i j}(s, t)\right]$ from our data set. Firstly, we introduce the following symbols:

$K$ is the number of independent trajectories in our data set;

$J_{n}^{r}$ is the state at $n$th transition of the $r$ th patient;

$T_{n}^{r}$ is the time in which the $r$ th subject makes the $n$th transition;

$A_{n}^{r}$ is the age at $n$th transition of the $r$ th patient;

$N^{r}=N^{r}(T)=\sup \left\{n \in N: T_{n}^{r} \leqslant T\right\}$ is the total number of transitions held by the $r$ th subject;

$N_{i}^{r}=N_{i}^{r}(T)=\sum_{k=1}^{N^{r}} \mathbf{1}_{\left\{J_{k-1}^{r}=i\right\}}$ is the number of visits of the $r$ th subject to state $i$;

$N_{i}=N_{i}(T)=\sum_{r=1}^{K} N_{i}^{r}$ is the total number of visits of all subjects to state $i$.

We consider the following empirical kernel estimator, on the analogy of that defined by Limnios and Oubhi (2005) in the homogeneous case:

$$
\hat{Q_{i j}}(s, t, K)=\frac{1}{N_{i}} \sum_{r=1}^{K} \sum_{l=1}^{N^{r}} \mathbf{1}_{\left\{J_{l-1}^{r}=i, J_{l}^{r}=j, A_{l-1}^{r}=s, A_{l}^{r} \leqslant t\right\}},
$$

in order to estimate the kernel (13) of the age dependence model and

$$
\hat{Q_{i j}}(s, t, K)=\frac{1}{N_{i}} \sum_{r=1}^{K} \sum_{l=1}^{N^{r}} \mathbf{1}_{\left\{J_{l-1}^{r}=i, J_{l}^{r}=j, T_{l-1}^{r}=s, T_{l}^{r} \leqslant t\right\}}
$$

in order to estimate the kernel (14) of the chronological time dependence model.

When the kernel (15) is used we discretized the time in years and the analysis is performed using the patient age as the time scale.

When the kernel (16) is used the analysis is performed using the chronological time as the time scale.

\section{Results}

As is well known from the Markov renewal process it is possible to define the semiMarkov process denoting the state occupied by $J_{n}$ for each waiting time. The evolution of the semi-Markov process is fully determined by the kernel (2), (13) or (14) depending on the implemented model.

\subsection{Patient's Age Dependence Results}

After the kernel has been estimated from dataset using estimator (15) it is possible to solve the corresponding evolution equation and compute several indicators useful to forecast the disease evolution. 


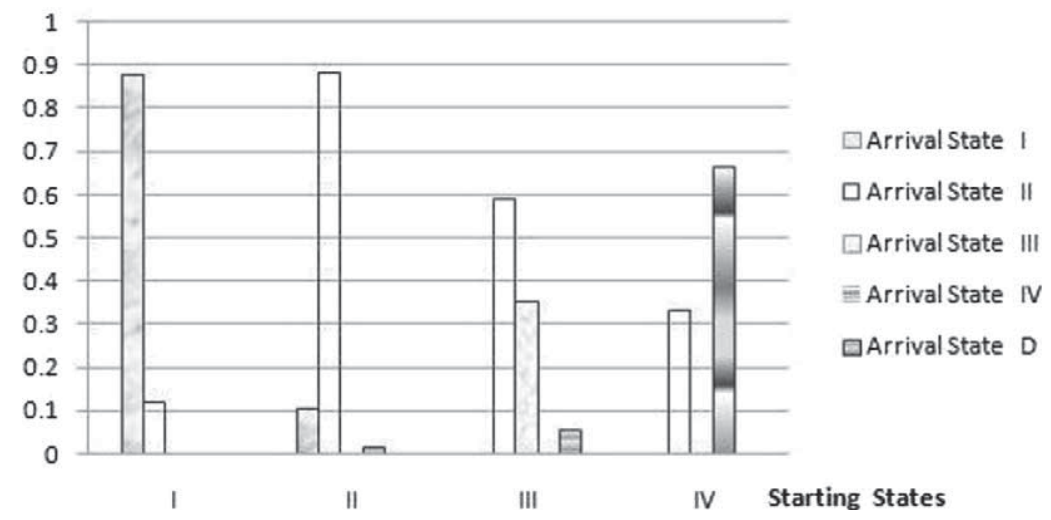

Fig. 2. Transition probabilities from age 26 to age 27.

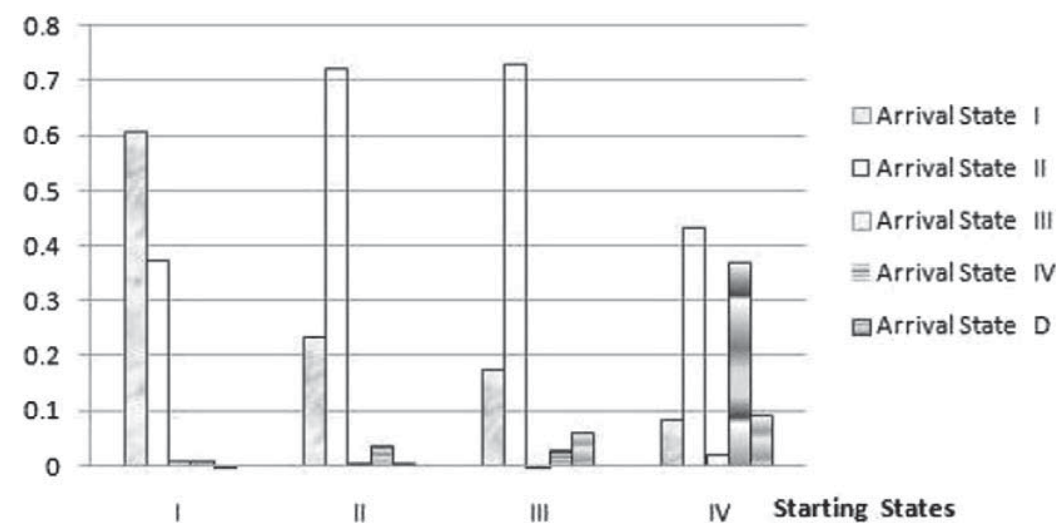

Fig. 3. Transition probabilities from age 26 to age 31

For lack of space it is no possible to show all results. In Figs. 2 and 3 there are some of the transitions probabilities. In particular the pictures show the conditional probabilities to get, respectively, state $j$ at ages 27 and 31 if the patient entered state $i$ at age 26 .

Figures 4 and 5 show the conditional probabilities to get, respectively, state $j$ at ages 45 and 49 if the patient entered state $i$ at age 44 .

Figures 6 and 7 show some of the survival functions. In particular in Fig. 6 there are the probabilities to survive up to ages 26,27, 28, 29 and 30 given that the patient entered state $i$ being aged 25, whereas in Fig. 7 there are the probabilities to survive up to ages 45, 46, 47, 48 and 49 given that the patient entered state $i$ being aged 44 .

Finally in Figs. 8 and 9 some of the failure rates are shown.

From Figs. 2, 3, 4 and 5 it is possible to verify the validity of the non homogeneity hypothesis. Indeed the transition probabilities are different when the age changes. For example for a patient 26 old it is likelier to make a transition in states II or III starting from III or IV with respect to a 44 years old patient. This effect remains when longer time horizon are considered. 


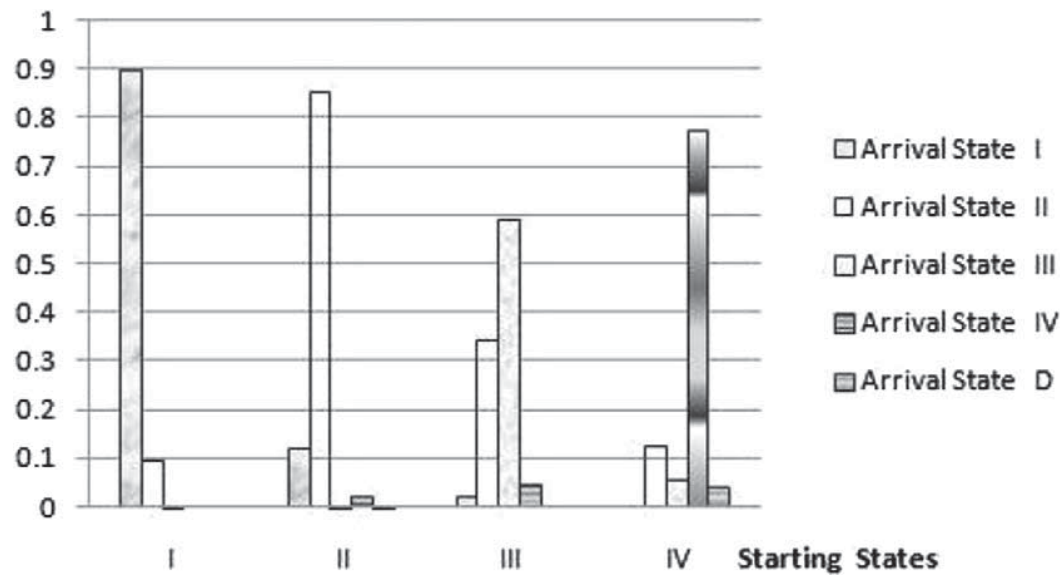

Fig. 4. Transition probabilities from age 44 to age 45 .

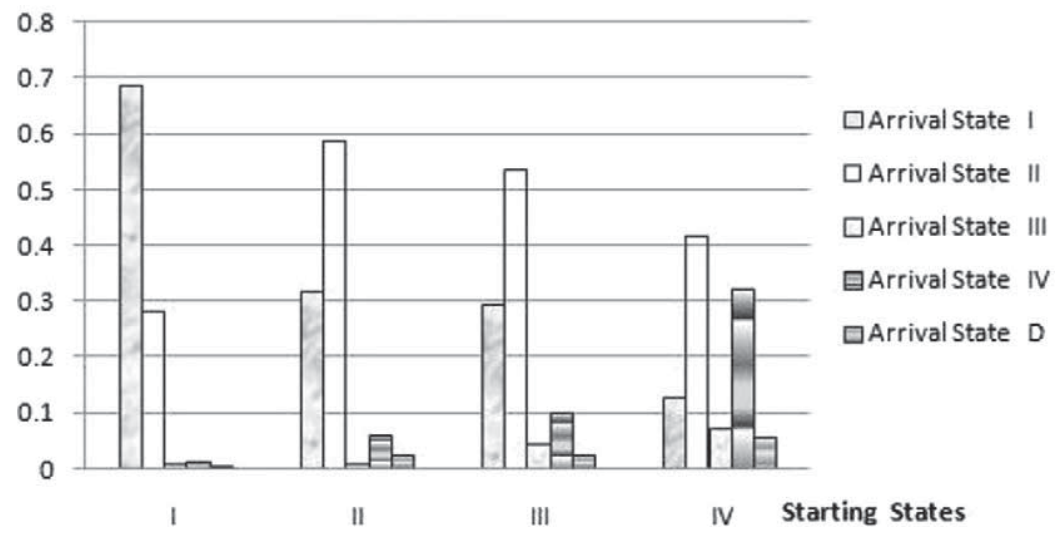

Fig. 5. Transition probabilities from age 44 to age 49 .

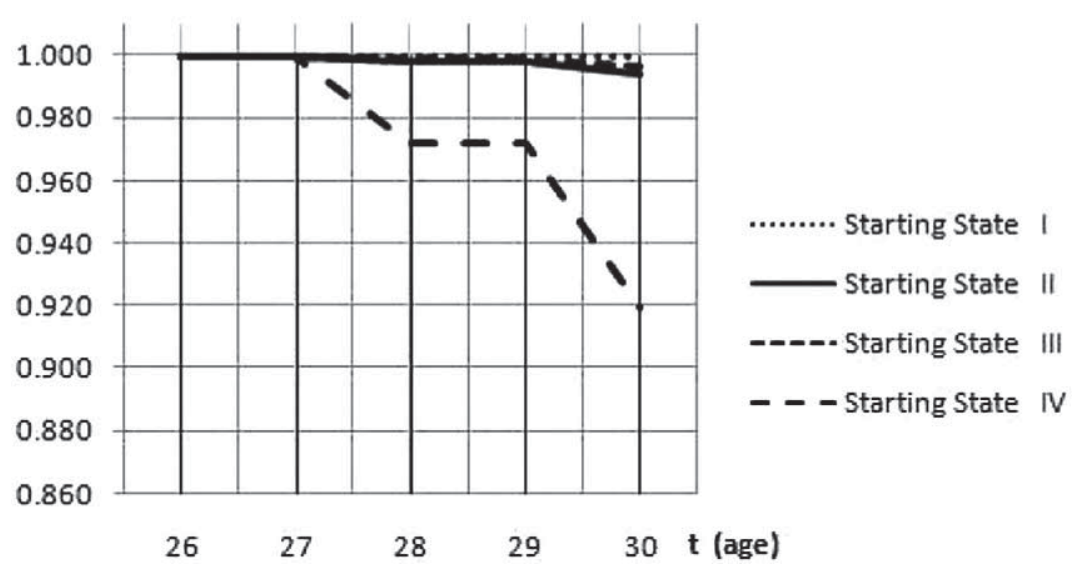

Fig. 6. Survival functions from age 25 to age 30 . 


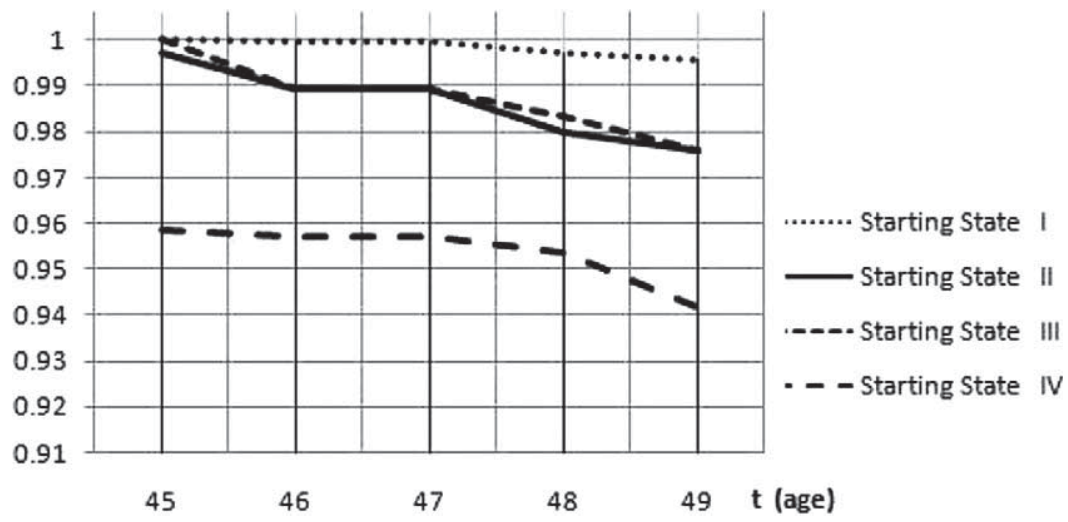

Fig. 7. Survival functions from age 44 to age 49 .

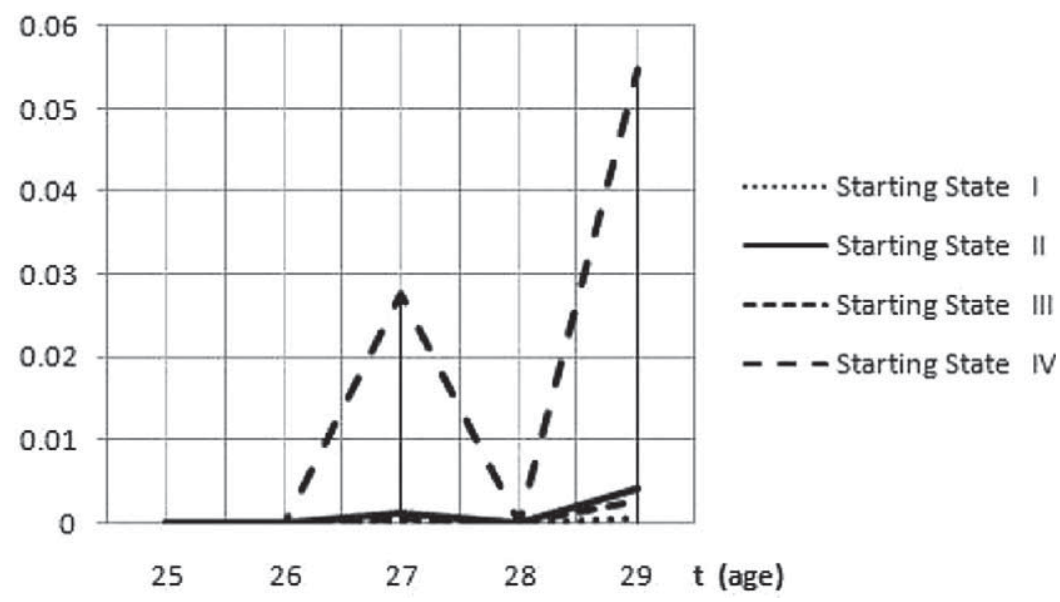

Fig. 8. Failure rates from ages 24 to age 29 .

As expected, from survival function examination in Figs. 6 and 7, the state I results the best and state IV the worst. Not many differences appear between states II and III for each age.

Figures 8 and 9 reveal that young patients $(s=24)$ have low death probabilities during the earlier disease years but after $4-5$ years these probabilities increase significantly. On the other hand the older patients $(s=44)$ have high death probabilities during the earlier disease years but after the risk decrease.

\subsection{Chronological Time Dependence Results}

In this model the kernel has to be estimated by (16). The bars shown in Figs. 10 and 11 represent the probabilities to get, respectively, state $j$ at chronological times 1992 and 1996 if the patient entered state $i$ in 1991. 


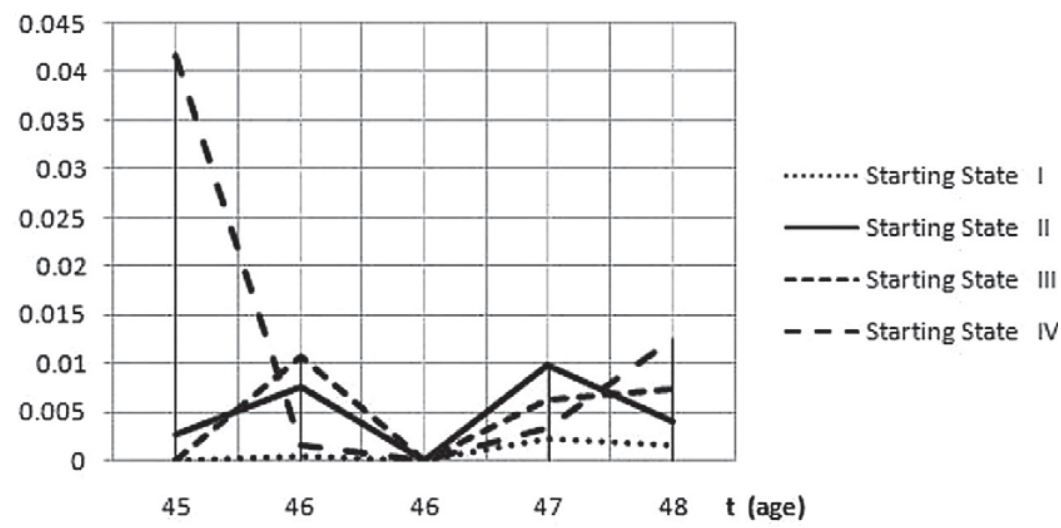

Fig. 9. Failure rates from ages 44 to age 48 .

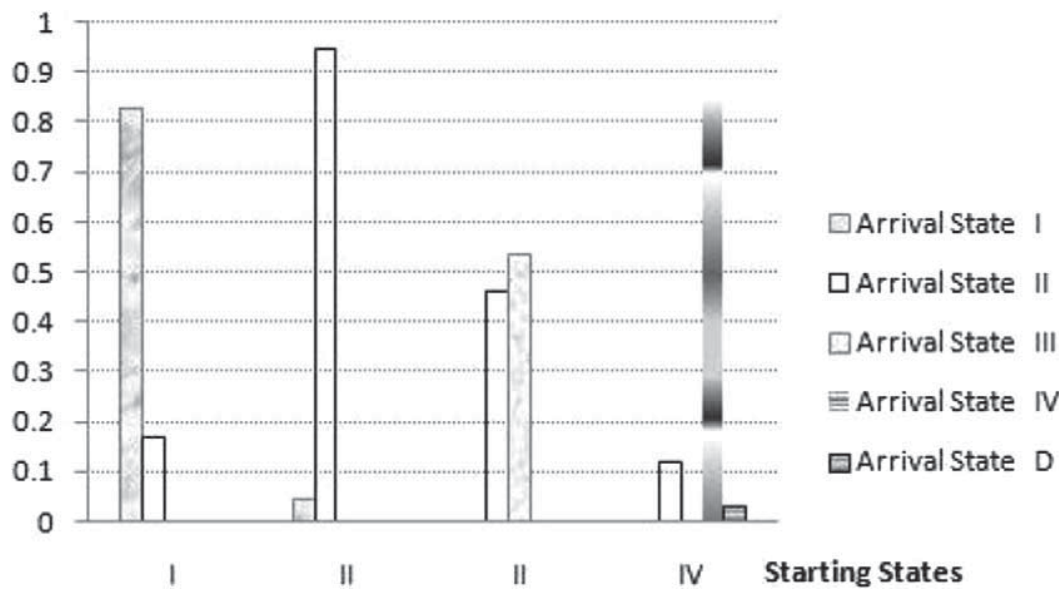

Fig. 10. Transition probabilities from 1991 to 1992.

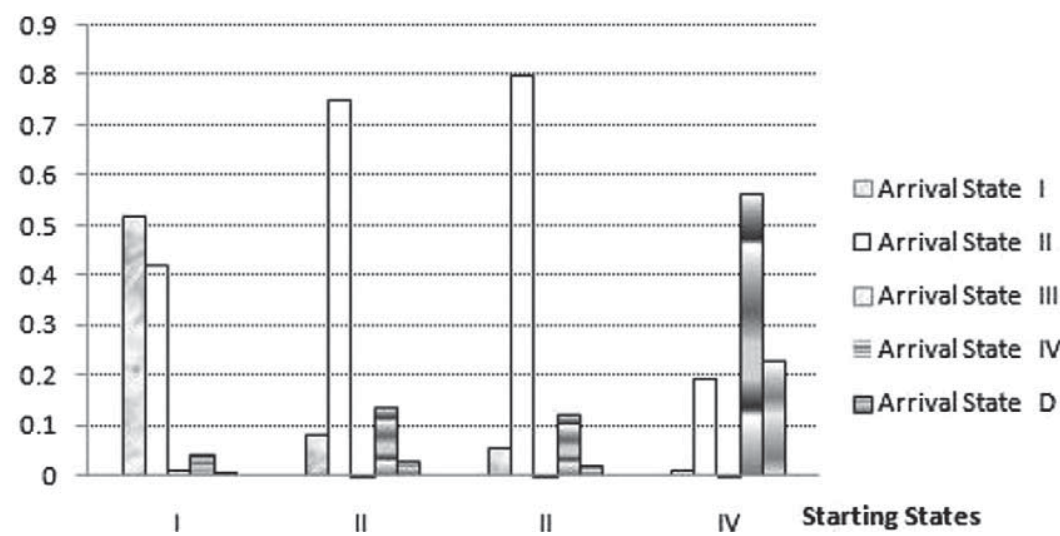

Fig. 11. Transition probabilities from 1991 to 1996. 
Figures 12 and 13 show the probabilities to get, respectively, state $j$ at times 2001 and 2005 if the patient entered state $i$ in 2000 .

Figures 14 and 15 show some of the survival functions. In particular in Fig. 14 there are the probabilities to survive up to 1992, 1993, 1994, 1995 and 1996 given that the patient entered state $i$ in 1991. In Fig. 15 there are the probabilities to survive up to 2001, 2002, 2003, 2004 and 2005 given that the patient entered state $i$ in 2000.

Finally in Figs. 16 and 17 some of the failure rates are shown.

From Figs. 10, 11, 12 and 13 it is possible to verify that to get HIV-infection in 1991 is worse than in 2000. Indeed the probabilities to make transitions into state D are greater in 1991 than in 2000. Moreover for each starting state in 2000 there is a great probability to recover state I. This effect is considerably weaker in 1991.

As expected, from survival function examination in Figs. 14 and 15, the state I results the best and state IV the worst. Now the medical progress effect reveals that state II is preferable to state III.

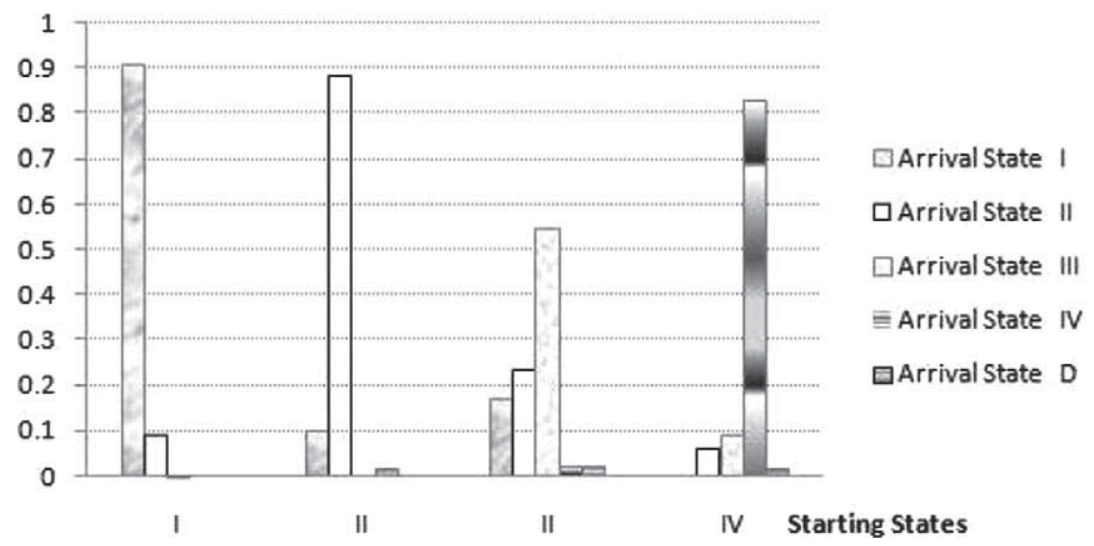

Fig. 12. Transition probabilities from 2000 to 2001.

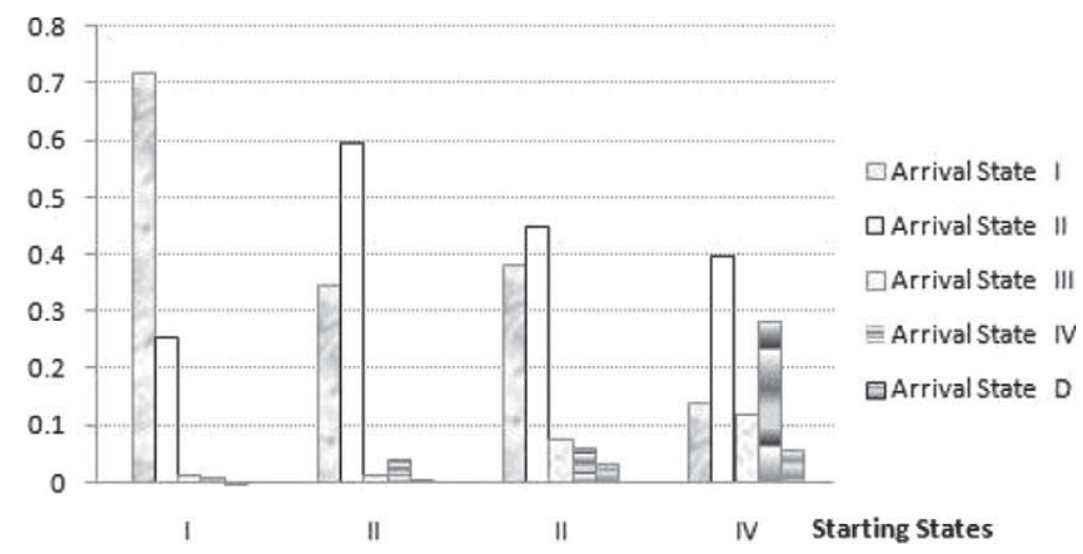

Fig. 13. Transition probabilities from 2000 to 2005. 


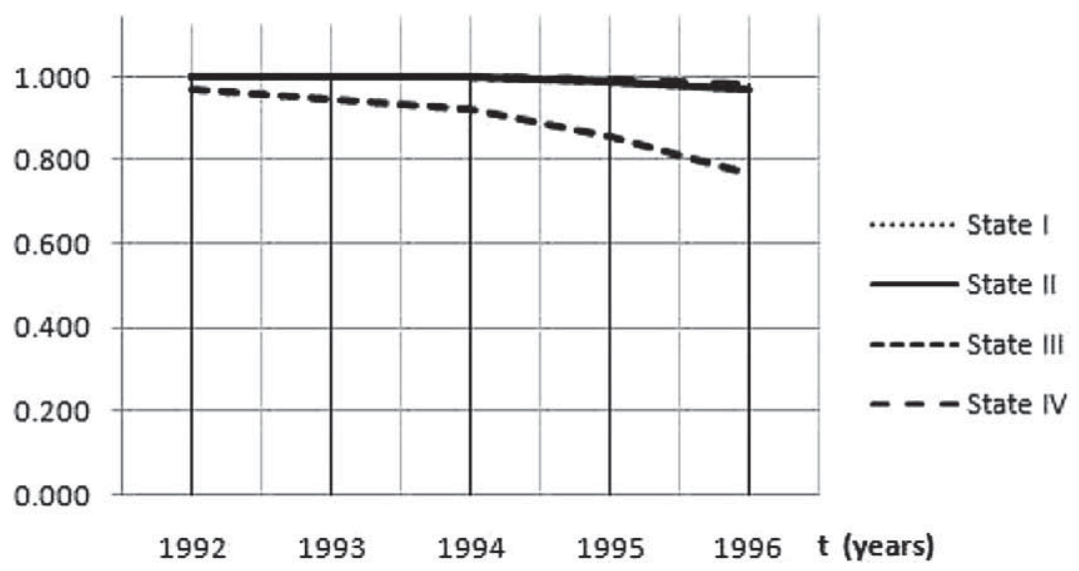

Fig. 14. Survival functions from time 1991 to time 1996.

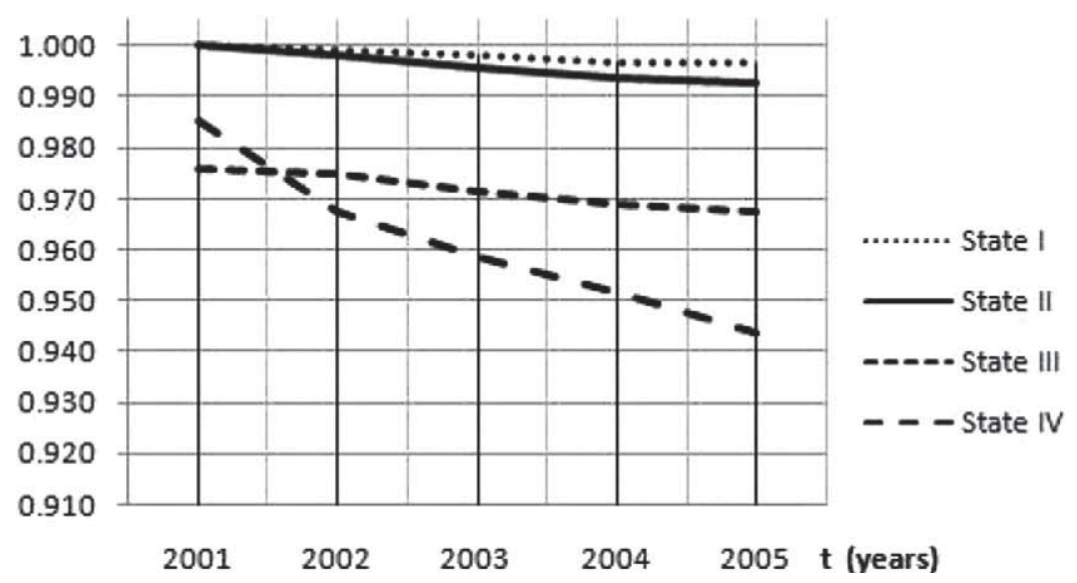

Fig. 15. Survival functions from time 2000 to time 2005 .

Figures 16 and 17 reveal that as time goes on the death rates increase when a patient become infected in 1991. On the other hand an infection held in 2000 will show higher death rates during the earlier disease years but after the risk decrease due to the medical treatment.

Due to lack of space, we do not show all the results which are available upon request.

\section{Concluding Remarks}

In this paper, a non homogeneous semi-Markov processes approach to the dynamic evolution of the Human Immunodeficiency Virus Infection, as defined by CD4+ levels and viral load, has been presented. Among the large number of results obtainable by our model, there are also the probabilities of an infected patient's survival taking into account the pa- 


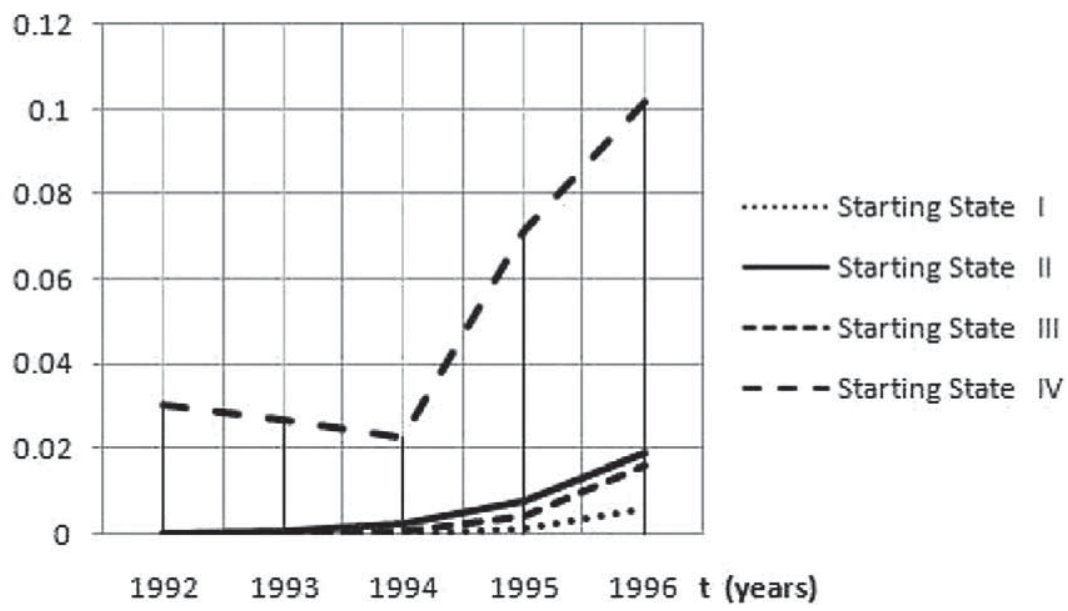

Fig. 16. Failure rate from 1991 to 1996.

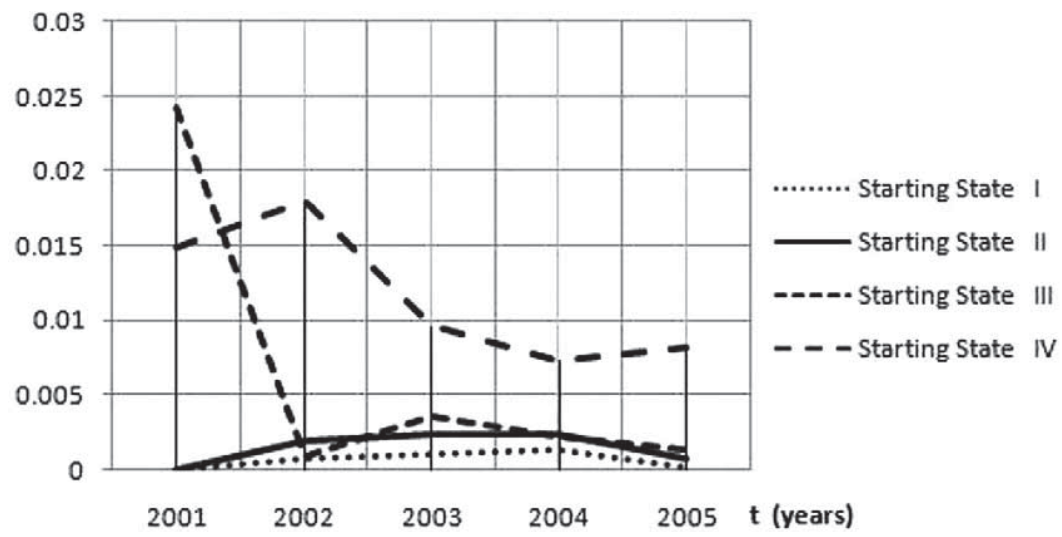

Fig. 17. Failure rate from 2000 to 2005.

tient's age and the survival functions taking into account the chronological time. Indeed, by means of the non-homogeneous model it is possible to study the dynamic evolution of the infection differentiated according to the patient's age and the scientific medical progresses due to the elapsing of time. In this way the model could be useful in order to manage the flows of patients towards hospital; in this regards it could be interesting the applications of methods proposed by Echague and Cholvi, 2010. As the results show, enormous advances in the treatment of HIV positive patients, have been obtained. Moreover also the age of the infected patients significantly diversifies the disease evolution.

In order to reach this goals the model has been implemented considering two different temporal scales.

We would like to underline that this paper does not show all the possibilities of the semi-Markov approach. In fact, by means of the backward recurrence time process it is possible to assess different transition probabilities as a function of the duration inside the 
states. Moreover, by attaching a reward structure to the process, it is possible to carry out a cost analysis considering, for example, the cost of anti-retroviral treatment and/or other social costs related to the dynamic evolution of the HIV infection. This will be the object of future research.

Acknowledgments. The authors are grateful to doctors Giovanni Rezza and Maria Dorrucci, Istituto Superiore di Sanità, Viale Regina Elena 299, 00161 Roma, Italy, for their helpfulness to retrieve the sanitary data.

\section{References}

Andersen, P.K., Borgan, O., Gill, R.D., Keiding, N. (1993). Statistical Models Based on Counting Processes. New York, Springer.

Barbu, V., Boussemart, M., Limnios, N. (2004). Discrete time semi-Markov model for reliability and survival analysis. Communications in Statistics: Theory and Methods, 33, 2833-2868.

Blasi, A., Janssen, J., Manca R. (2004). Numerical treatment of homogeneous and non-homogeneous reliability semi-Markov models. Communications in Statistics: Theory and Methods, 33, 697-714.

Dabrowska, D.M., Ho, W. (2006). Estimation in a semi parametric modulated renewal process. Statistica Sinica, $16,93-119$.

Davidov, O., Zelen, M. (2000). Designing cancer prevention trials: a stochastic approach. Statistics in Medicine, 19, 1983-1995.

D’Amico, G., Janssen, J., Manca, R. (2010). Discrete time non-homogeneous semi-Markov reliability transition credit risk models and the default distribution functions. Computational Economics. doi: 10.1007/s10614010-9219-x.

Di Biase G., D’Amico G., Di Girolamo A., Janssen J., Iacobelli S., Tinari N., Manca R. (2007). A stochastic model for the HIV/AIDS dynamic evolution. Mathematical Problems in Engineering, Art. ID 65636. doi: $10.1155 / 2007 / 65636$

Echague, J., Cholvi, V. (2010). Tight arrival curve at the output of a work-conserving blind multiplexing server. Informatica, 21(1), 31-40.

Foucher, Y., Mathieu, E., Saint-Pierre, P., Durand, J.F., Daures, J.P. (2005). A semi-Markov model based on generalized Weibull distribution with an illustration for HIV disease. Biometrical Journal, 47, 825-833.

Gill, R.D. (1980). Nonparametric estimation based on censored observations of a Markov renewal process. Zeitschrift für Wahrscheinlichkeitstheorie und Vervandte Gebiete, 53, 97-116.

Jannsen, J., Manca, R. (1997). A realistic non-homogeneous stochastic pension funds model on scenario basis Scandinavian Actuarial Journal, 113-137.

Limnios, N., Oubhi, B. (2005). Nonparametric estimation for semi-Markov processes based on $k$-sample paths with application to reliability. In: Janssen, J., Lenca, P. (Eds), Proc. of the XI ASMDA, 2005 Conference, Brest, France, pp. 1061-1068.

Maciulis, A., Paunksnis, A., Barzdziukas, V., Kriauciuniene, L., Buteikiene, D., Puziene, V. (2009). Digital model of blood circulation analysis system. Informatica, 20(4), 539-554.

Mathieu, E., Foucher, Y., Dellamonica, P., Daures, J.P. (2007). Parametric and non homogeneous semi-Markov process for HIV control. Methodology and Computing Applied Probability, 9, 389-397.

Ouhbi, B., Limnios, N. (1999). Nonparametric estimation for semi-Markov processes based on its hazard rate functions. Statistical Inference for Stochastic Processes, 2, 151-173. 
G. D'Amico received his degree in economics from G. D'Annunzio University of Chieti and $\mathrm{PhD}$ in mathematics for the applications in economics, finance and insurance from the University La Sapienza of Rome. He is currently an assistant professor in mathematical methods for economics, finance and insurance at the G. D'Annunzio University of Chieti (Italy). His research interests are in nonparametric statistics, theory of stochastic processes, stochastic modeling and their applications in finance, insurance, economics, reliability and biomathematics.

G. Di Biase received his degree in civil engineering from the University of Bologna, Italy. $\mathrm{He}$ is currently an associate professor of mathematical method for economics, finance and insurance at the University G. D'Annunzio of Chieti, Italy. His research interests are in artificial intelligence, stochastic processes, stochastic modeling and their applications in finance, insurance, economics, reliability and biomathematics.

J. Jannsen worked in the following universities: Université Libre de Bruxelles, Vrije Universiteit Brussel, Université de Bretagne Occidentale (EURIA), Universités de Paris 1 (La Sorbonne) and Paris VI (ISUP), ENST-Bretagne, Université de Strasbourg and the Universities of Rome (La Sapienza), Firenze and Pescara. His research interests are in theory of stochastic processes, stochastic modeling and their applications in finance, insurance, economics, reliability and biomathematics.

R. Manca received his degree in economics from University of Neaples, Italy. He is currently full professor of mathematical method for economics, finance and insurance at the University La Sapienza of Rome, Italy. His research interests are in manpower planning, linear algebra, theory of stochastic processes, stochastic modeling and their applications in finance, insurance, economics, reliability and biomathematics.

\title{
ŽIV evoliucija: efekto dèl amžiaus ir medicinos progreso tyrimas
}

\author{
Guglielmo D'AMICO, Giuseppe DI BIASE, Jacques JANSSEN, Raimondo MANCA
}

Šis straipsnis tiria ŽIV/AIDS dynamika, apibrèžtą CD4 lygiais ir virusine apkrova, modeliuojama makroskopiniu požiūriu stochastiniais procesais. Modelis atsižvelgia ị paciento amžiu kaip i tinkamą veiksnị nuspèti realiu laiku perejimams tarp skirtingo sunkumo susirgimo lygiụ. Kitame modelyje nagrinėjami abu minèti veiksniai kartu. Tokiu būdu tampa ịmanoma ịvertinti medicinos mokslo progresą atsižvelgiant ị pokyčius gydant ŽIV. Analizei taikomi nehomogeniniai Markovo procesai. Šie modeliai įdiegti pasinaudojus realiais ISS (Istituto Superiore di Sanitá, Roma, Italija) duomenimis. Juose nagrinėjami 2159 atvejai, užregistruoti Italijos viešosiose struktūrose nuo 1983 m. rugsejjo iki 2006 m. sausio. Atitinkami rezultatai atsižvelgia ị užkrèstų pacientų išgyvenamumo analizę. Apskaičiuotos sąlyginès tikimybès parodo skirtingą subjektų atsaką priklausomai nuo amžiaus ir praèjusị nuo užkrètimo laiką. 